\title{
Invited review: Abomasal damage in veal calves
}

\author{
J. D. Bus, ${ }^{1}$ N. Stockhofe ${ }^{2}$ and L. E. Webb ${ }^{1 *}$ \\ ${ }^{1}$ Animal Production Systems Group, Wageningen University and Research, PO Box 338, 6700 AH Wageningen, the Netherlands \\ ${ }^{2}$ Wageningen Bioveterinary Research, Wageningen University and Research, PO Box 65, 8200 AB Lelystad, the Netherlands
}

\section{ABSTRACT}

Within all cattle production systems, veal calves are the most severely affected by abomasal damage, with current prevalence at slaughter ranging from 70 to $93 \%$ of all animals affected. Although most damage is found in the pyloric region of the abomasum, fundic lesions are also found. Despite past research into the etiology of abomasal damage and the many risk factors that have been proposed, consensus on the causal factors of abomasal damage in veal calves has not yet been reached. The aim of this review was to integrate and analyze available information on the etiology of, and possible risk factors for, abomasal damage in veal calves. We describe various proposed pathways through which risk factors may contribute to damage formation and conclude that the etiology of abomasal damage is most likely multifactorial, with diet being a main contributor. Pyloric lesions, the most common type of damage in veal calves, are likely the result of large and infrequent milk and solid feed meals, whereas fundic lesions may be caused by stress, although the evidence for this is inconclusive. Providing calves with multiple smaller milk and solid feed meals (or ad libitum provision) may decrease abomasal damage. In future research, ulcers, erosions, and scars as well as fundic and pyloric lesions should be recorded separately, because etiologies of these may differ. Further research is required to understand the exact pathway(s) by which milk replacer causes abomasal damage in veal calves; that is, whether low abomasal pH, overloading, or composition are important. Further research is also required to elucidate whether rapid intake of milk replacer and solid feed, which is influenced by restricted amounts fed, inter-calf competition, and calf breed, increases abomasal damage. Research is also needed into the effect of medication and nutrient deficiencies other than iron. The types of experimental designs that can be used for future research could be enhanced if a means to

Received June 28, 2018.

Accepted November 1, 2018.

*Corresponding author: laura.webb@wur.nl assess abomasal damage antemortem is developed. We conclude that it is unlikely that abomasal or ruminal hairballs, iron deficiency, water provision, and various infections and diseases are significant contributors to abomasal damage in veal calves.

Key words: abomasal damage, veal calf, etiology, risk factor

\section{INTRODUCTION}

Abomasal damage involves lesions of the inner wall of the ruminant abomasum, which include minor perturbations or more severe damage causing bleeding or perforation of the wall and subsequent peritonitis. Abomasal damage is a problem in cattle of all ages and all production systems, with "white" veal calves (hereafter, veal calves) being most affected (e.g., Brscic et al., 2011; Kureljušić et al., 2013; Hund et al., 2016). Abomasal damage in the form of lesions can cause high mortality rates of, for example, between 0.53 and $0.11 \%$ in veal calves in Switzerland and Belgium (Bähler et al., 2012; Pardon et al., 2012a). The mortality rates only reflect the most extreme forms of abomasal damage - perforating ulcers - and hence represent only the tip of the iceberg. Average reported prevalence of nonfatal damage at slaughter ranged from 70 to $93 \%$ of veal calves in Europe (Bähler et al., 2010; Brscic et al., 2011). Certain veal farms in Europe have reported $100 \%$ prevalence for abomasal damage (Brscic et al., 2011). Veal calves are reared on a diet made up of milk replacer (MR), supplemented by moderate amounts of solid feed (SF) with a high percentage of concentrate (at least in Europe since 1997), until a slaughter age of approximately 6 mo and a BW of approximately 200 to $250 \mathrm{~kg}$. The MR is typically fed in buckets or troughs twice a day, although some farms use automated milk dispensers, which allow more frequent feedings (typically 3 meals per day; Bokkers and Koene, 2001; Brscic et al., 2011). The SF is generally only fed after the morning MR meal, in the same container as the MR, once the MR has been consumed. This diet of mostly iron-poor MR and concentrate ensures low blood hemoglobin levels and the pale color of the veal. 
The exact implications of abomasal damage for calf welfare are not fully understood. Whether calves experience pain due to nonperforating abomasal damage has not been determined. In most cases, the presence of abomasal damage is not associated with clinical signs (Veissier et al., 1998; Marshall, 2009; Hund et al., 2016), unless the lesions are severe enough to perforate the abomasal wall or cause hemorrhage (Smith et al., 1983, 1986). Commonly, affected veal calves are found dead in the stable or lesions are only identified at slaughter (Marshall, 2009). Mortality following abomasal perforation, of course, does present a welfare issue. Although it has been proposed that (nonperforating) abomasal damage may reduce feed intake and thus lead to decreased growth and economic losses (Tajik et al., 2012), most studies have been unable to identify a reduction in growth (Welchman and Baust, 1987; Breukink et al., 1989; Bähler et al., 2010).

Many articles have addressed the causes and predisposing factors of abomasal damage in veal calves and, although no consensus has yet been reached, it is generally accepted that the etiology is multifactorial. The aim of this systematic review is to integrate and analyze the available information on the etiology of, and possible risk factors for, abomasal damage in veal calves. The literature search was conducted from January to April 2017 using the search engine Web of Science, and included the following search terms: Abomas* AND (damage OR ulcer* OR lesion* OR scar*). In addition, the technique of snowballing references (using the reference list of a paper to identify additional papers) was applied. Titles and abstracts were scanned, during which papers referring to non-bovine species or not in English or Dutch were discarded. When no articles on bovines could be identified on a specific mechanism of interest, other ruminant and monogastric articles were used. These other articles were selected based on relevance to the mechanisms of interest only, given that often very few papers were written on the topics we sought, with a preference for ruminant species over monogastric species. Because the fourth stomach compartment of the ruminant, the abomasum, is functionally similar to the monogastric stomach, it may be that knowledge of gastric ulcers extends to abomasal ulcers, although this should be approached cautiously. For some articles, only the abstract could be obtained. This led to 122 articles being evaluated for this review. Despite the fact that veal production systems have changed substantially over the past decades, older literature was included, because experimental studies from that time are often still relevant. This review is divided in 4 parts, covering the association between abomasal damage in veal calves and (1) nutritional factors, (2) stress, (3) diseases, and (4) other miscel- laneous factors such as breed and season. We will begin with an overview of lesion type and localization and end by proposing paths for future research.

\section{ANATOMICAL LOCALIZATION AND LESION TYPE}

In veal calves, abomasal damage has been commonly described as consisting of 3 types of lesions: erosions, ulcers, and scars (e.g., Wiepkema et al., 1987; Veissier et al., 1998; Webb et al., 2013), although other methods, such as estimated surface area, have recently been applied to record lesion severity (Berends et al., 2014). In this review, we will distinguish between erosions, ulcers, and scars, as these may have slightly different etiologies because of differences in location. Erosions are local defects of the mucosal layer that have not yet penetrated the lamina muscularis mucosae, the thin layer of smooth muscle that separates the lamina propria from the submucosa (Mattiello et al., 2002; Marshall, 2009; Webb et al., 2013). They are small compared with ulcers, usually only 1 to $20 \mathrm{~mm}$ in diameter (Sun, 1974; Smith et al., 1983), with more recent studies reporting mean erosion sizes of $0.7 \mathrm{~cm}^{2}$ (Webb et al., 2013). In addition, erosions are likely to have a lower prevalence than ulcers (Webb et al., 2013). Ulcers are lesions of the abomasal mucosa that penetrate into the submucosa and range from a few millimeters to several centimeters in size (Mattiello et al., 2002; Marshall, 2009; Webb et al., 2013). Ulcers can cause perforation of the abomasal wall, which can lead to inflammation and infection of the peritoneum (peritonitis), the membrane that forms the lining of the abdominal cavity (Jensen et al., 1976; Tanwar et al., 2009). Ulcers have been classified into 4 types. Type 1 ulcers are nonperforating ulcers that come without extensive bleeding; type 2 ulcers are nonperforating and involve (severe) blood loss; type 3 ulcers are perforating with local peritonitis; and type 4 ulcers are perforating with diffuse peritonitis (Smith et al., 1983; Marshall, 2009; Van Immerseel et al., 2010). Most experimental studies, however, did not use the latter classification to distinguish between ulcer types. Scars are thought to be healed ulcers, partially because they are found in a similar location and are fibrous contractions of the mucosa (Degen, 1982, as cited by Wiepkema et al., 1987; Webb et al., 2013). When abomasal ulcers heal, the wound contracts and new scar tissue is synthesized (Smith et al., 1983). No scar tissue is formed in the healing process of erosions because erosions heal using epithelial regeneration, which does not involve the formation of scar tissue (Sun, 1974, as cited by Smith et al., 1983). In veal calves, abomasal damage is mostly found in the pyloric region of the abomasum (Lourens et al., 1985; De Wilt, 1985; Welchman, 1986; Pearson et al., 1987; Breukink et al., 1989; Veissier et 
al., 1998; Marshall, 2009). Nevertheless, erosions can also be found scattered throughout the abomasum (Wiepkema et al., 1987) and in the fundic region, though with lower prevalence and severity (Groth and Berner, 1971 as cited by Welchman and Baust, 1987; Bähler et al., 2010; Valgaeren et al., 2013).

\section{FACTORS ASSOCIATED WITH NUTRITION}

A complete overview of all factors associated with nutrition and their possible role in the development of abomasal damage in veal calves is presented in Table 1.

\section{Milk Replacer}

In the past, European veal calves were fed only MR, until European legislation mandated the provision of fibrous feed in addition to MR in 1997 (European Union Directive 97/2/EC). At slaughter, it was observed that many of the calves fed only MR were suffering from abomasal lesions, with a prevalence of up to $70 \%$ (Wensing et al., 1986; Wiepkema et al., 1987). An MRonly diet was typically fed in 2 meals per day, and increased linearly in volume throughout the fattening period, ending with provision of approximately $3 \mathrm{~kg}$ of MR powder per day (Prevedello et al., 2012; Webb et al., 2013). The provision of MR has now decreased because of the mandatory provision of SF, the latter being generally provided above the European Union's requirement of 50 to $250 \mathrm{~g} / \mathrm{d}$ (Brscic et al., 2011). The theory is that an MR-only diet causes abomasal lesions via abomasal overloading or low abomasal $\mathrm{pH}$; however, this has never been studied experimentally and, without further research, it is impossible to know whether these pathways are indeed accurate. Below we present the proposed mechanisms behind these 2 theories and some indirect evidence in support of, or contradicting, these theories. The term "milk" will be used when both MR and whole milk are discussed together or when the distinction is not important. Although overloading and $\mathrm{pH}$ are the most mentioned theories in relation to the effect of MR on abomasal damage, the specific milk composition might also affect abomasal damage. No research could be found on the effect of MR composition on abomasal damage; nonetheless, composition will affect the clotting potential of the MR, which might, in some way, affect abomasal damage. This area warrants future attention.

Abomasal Overloading. As explained above, most lesions in veal calves are found near the torus pylorus, which controls the passage of abomasal contents into the duodenum and which is a site of peristalsis and segmentation. Overloading of the abomasum could cause localized hypoxia in the pyloric region (Lourens et al.,
1985; Breukink et al., 1991): the pathway is proposed to start with an increase in the tonus of the abomasal muscles, leading to peristaltic contractions that are strongest around the pylorus. Both these contractions and direct pressure exerted on the abomasal wall by a large milk volume could lead to compression of the mucosa and blood vessels and subsequent oxygen shortage. Over time, damaged sites could develop into erosions and ulcers, although the exact pathway for this is unclear. Current evidence is insufficient to support this theory. The only findings in favor of the overloading theory are 3 articles providing some indirect evidence: Veissier et al. (1998) found that group-housed calves that (probably) drank their MR meal faster had more pyloric lesions than individually housed calves that (probably) drank their MR slower; and Bähler et al. (2010) and Welchman and Baust (1987) found that the heaviest calves, hence possibly dominant, faster-drinking calves, developed the most pyloric (but not fundic) lesions. Two articles opposing the overloading theory are Berends et al. (2014), who found that decreasing milk meal size while simultaneously increasing the concentrate part of the diet caused worse damage (experimental study), and Brscic et al. (2011), who found that calves receiving relatively low amounts of MR had a higher risk for lesions (risk assessment study).

Low Abomasal $p H$. In rats, horses, and humans, a low gastric $\mathrm{pH}$ has been associated with a higher frequency of gastric ulceration or eroding (Nagamachi and Skoryna, 1977; Murray, 1999; Uchida et al., 1999). In adult beef cattle, a lower $\mathrm{pH}$ has been associated with more abomasal erosion (Jensen et al., 1992), which has led to the proposition that $\mathrm{pH}$ may also be an important factor in abomasal damage in calves (Ahmed et al., 2002; Marshall, 2009). There is no direct evidence currently for this, however. In fact, Hund et al. (2016) reported no difference in lumen $\mathrm{pH}$ between damaged and intact abomasa of slaughtered bulls, cows, and (nonveal) calves. Pathways explaining the possible relationship between low abomasal $\mathrm{pH}$ and abomasal damage are as follows: (1) excessive activation of the proenzyme pepsinogen into pepsin, whereby the proteolytic activity of pepsin may break through the barriers protecting the abomasal wall and cause lesion of mucosal proteins (Nagamachi and Skoryna, 1977; Ahmed et al., 2002; Mesarič et al., 2002); and (2) compromised functioning of the mucus layer that protects the abomasal mucosa, which leads to decreased hydrogen carbonate production and increased back-diffusion of hydrogen ions into the abomasal wall, because fewer ions are neutralized by hydrogen carbonate before coming into contact with the wall (Nagamachi and Skoryna, 1977; Lourens et al., 1985; Yandrapu and Sarosiek, 2015). In support of the latter, mucin concentration was reported to be lower 
BUS ET AL.

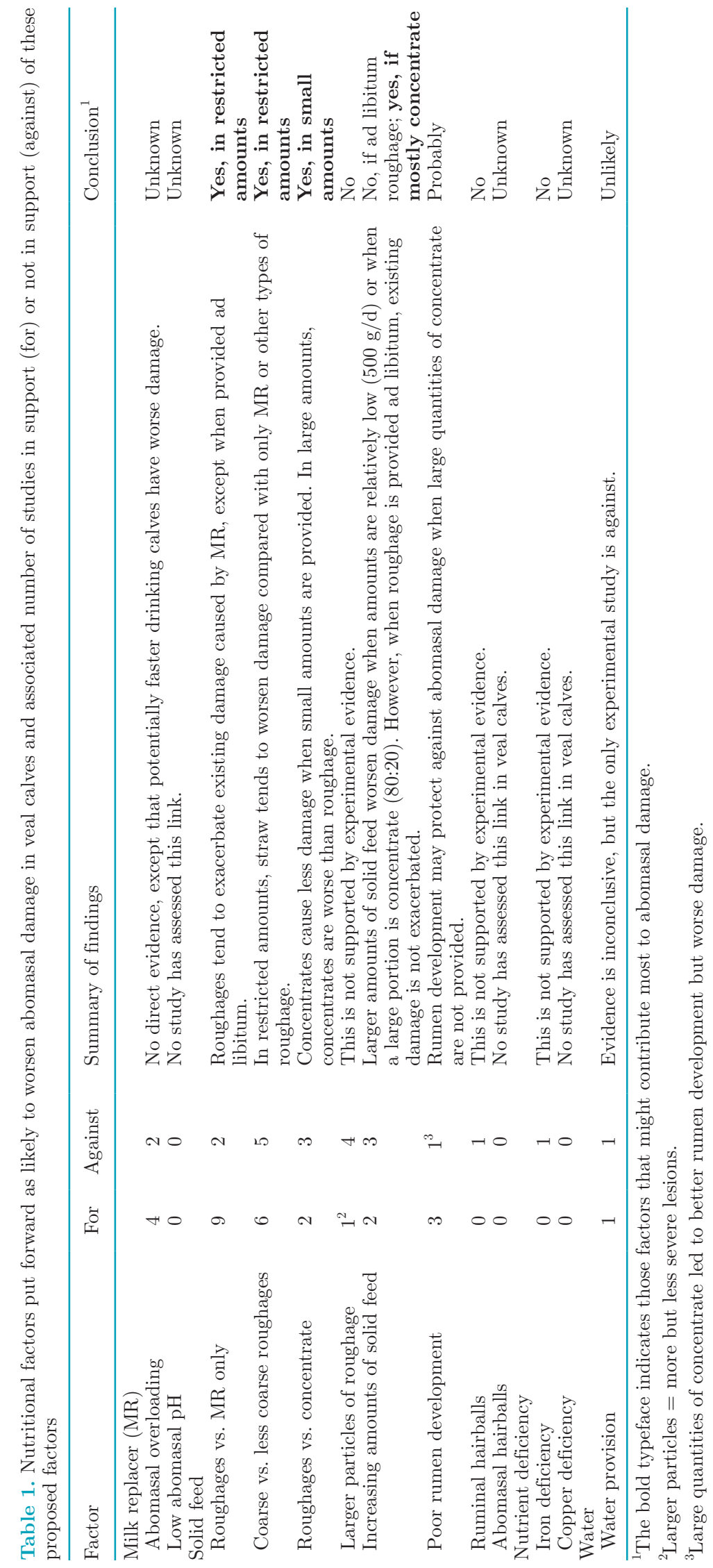


at damaged sites (Pearson et al., 1987; Breukink et al., 1991) and in the pyloric region (Lourens et al., 1985), the region in which most damage occurs in veal calves.

Indirect evidence that $\mathrm{pH}$ may play a role in the development of abomasal damage is the successful treatment of abomasal and gastric ulcers using medication that increases abomasal $\mathrm{pH}$, either by neutralizing secreted $\mathrm{HCl}$ or by decreasing $\mathrm{HCl}$ secretion, in other mammals (adult cattle: Tharwat and Ahmed, 2012; sheep: Morgado et al., 2014; musk-ox, moose, deer, and wapiti: Haigh, 1982; humans: Maton and Burton, 1999; Holle, 2010). Although medication can be used in the treatment of ulcers, lack of knowledge on their long-term (health) consequences limits its application as a preventive measure. Moreover, preventive administration of medication could be considered unethical. It should be noted that the $\mathrm{HCl}$-secretory cells, whose secretions cause abomasal acidity, develop only after a few days of life, possibly to prevent colostral antigens from being broken down (Lourens et al., 1985; Weiner, 1996; Guilloteau et al., 2009).

Abomasal luminal $\mathrm{pH}$ in calves depends on meal volume, sucking rate, abomasal emptying rate, acidity of the milk, and the buffering and clotting capacity of the milk (Woodford et al., 1987; Ahmed et al., 2002; Constable et al., 2005, 2006). Smaller milk volumes provided multiple times a day maintain a higher and more stable abomasal $\mathrm{pH}$ than infrequent large meals (Woodford et al., 1987; Ahmed et al., 2002). Normally, acidified MR would lead to a decreased abomasal $\mathrm{pH}$ compared with normal MR (Vajda et al., 2007); however, acidified MR can be provided ad libitum, leading to more frequent consumption (Webb et al., 2014), although not all studies support this (Hill et al., 2013). The clotting properties of the milk can affect abomasal $\mathrm{pH}$, because whole milk, which has a fast clotting capacity, allows for a lower $\mathrm{pH}$ than nonclotting MR (Constable et al., 2005). Hence, adjusting the milk regimen can affect abomasal $\mathrm{pH}$, and potentially abomasal damage, although no direct evidence has yet been presented for the latter.

\section{Solid Feed}

If $\mathrm{SF}$ is supplemented to an MR diet, the incidence of abomasal lesions is often observed to worsen (Wensing et al., 1986; Welchman and Baust, 1987; Breukink et al., 1991; Veissier et al., 2001; Mattiello et al., 2002; Cozzi et al., 2010; Berends et al., 2012; Prevedello et al., 2012; Webb et al., 2013). However, such an effect has not been found with all roughage types, quantities, and particle sizes. The current theory is that SF can exacerbate damage that has already been caused by large quantities of MR in two ways. The first pathway is by causing trauma, often referred to in the literature as abrasion, to the abomasal wall. The second pathway is by blocking the pylorus, thereby delaying digesta from leaving the abomasum and exacerbating abomasal overloading by extending the time during which large quantities remain in the abomasum (Welchman and Baust, 1987; Mattiello et al., 2002; Webb et al., 2013). The traumatizing capacity of SF is thought to be enhanced by the earlier mentioned increased peristaltic contractions caused by abomasal overloading with MR because those contractions lead to increased contact between the coarse SF and the abomasal wall (Lourens et al., 1985). The effects of SF on abomasal damage may depend on the SF type provided, its physical form, and the amount of SF fed.

Solid Feed Type. Roughage types fed to veal calves include wheat and barley straw, lucerne (or alfalfa), beet pulp, maize silage, and maize cob silage, although the high starch content of maize cob silage makes it similar to concentrate rather than roughage. With the exception of lucerne, these roughage types are chosen because they have a low iron content and thus minimally affect the hemoglobin level of the blood, which helps to preserve the pale color of veal. In research, hay is sometimes fed to veal calves, but this is rarely done on farms, because hay has a high iron content and will cause the meat to darken (Blokhuis, 2000). The effects of roughage on abomasal damage are not entirely clear. Studies have generally found that the feeding of straw, a very coarse roughage, exacerbates abomasal lesions (Van der Mei, 1985; Welchman and Baust, 1987; Breukink et al., 1991; Webb et al., 2013), although 5 studies do not support this (Van Putten, 1982; De Wilt, 1985; Veissier et al., 1998; Prevedello et al., 2012; Webb et al., 2015). The order of roughages from least to most deleterious appears to be hay < maize cob silage/beet pulp $<$ lucerne $<$ maize silage $<$ straw (Wensing et al., 1986; Breukink et al., 1991; Mattiello et al., 2002; Räber et al., 2013b; Webb et al., 2013). However, comparison between studies is difficult due to different amounts and particle sizes of roughage being fed. Interestingly, Räber et al. (2013a,b) found no significant difference in the pylorus between maize silage and straw but did find more lesions in the fundus of straw-fed calves.

Cereal grains, barley grains, whole-plant maize pellets, and pellet mixes (containing, for example, oat hulls, maize or barley grain, soy flakes or plant oils, and a pellet binder) are the types of concentrate that have been researched in veal calves for their effects on abomasal damage. However, most studies combined both concentrate and roughages in the diet. Only one study added solely concentrate to an MR diet and found a decreasing trend for lesion incidence compared with straw (Räber et al., 2013a). In addition, one study 
compared 2 concentrate types, and found no difference in lesion incidence between them (Räber et al., 2013b). Furthermore, feeding pellets of roughage and concentrate with 4 different compositions (differences were in the starch, fiber, crude protein, and ash contents) did not affect lesions $>0.5 \mathrm{~cm}$ (Morisse et al., 2000). Adding concentrate to roughage may prevent an increase in the lesion incidence that would normally happen with roughage (Morisse et al., 1999). However, some studies found no improvement or even a worsening of the damage with a combination of roughage and concentrate compared with only roughage (Berends et al., 2012; Prevedello et al., 2012). Very high levels of concentrate (concentrate:roughage $\geq 80: 20$ ) have been seen to lead to acute ulceration in beef calves (Tharwat and Ahmed, 2012) and can increase abomasal damage in veal calves as the amount fed increases, even when MR is decreased simultaneously (Berends et al., 2014). It should be noted that no studies used a larger relative proportion of roughage than concentrate, and therefore no general conclusion for all combinations of roughage and concentrate can be made.

The addition of specific feedstuffs, such as extruded pea, extruded soybean, or urea, has been researched to determine their value in adding protein or nitrogen to the diet without compromising veal color and quality. No effect on the incidence or severity of abomasal lesions was found with the addition of these feedstuffs (Prevedello et al., 2012; Brscic et al., 2014).

Physical Form of Solid Feed. A feedstuff can be provided in various physical forms. Roughage can be fed as large particles, chopped to a smaller particle size, ground, or included in a pellet. Different physical forms may have different traumatizing or blocking effects, and one might expect that larger particles are more blocking than shorter ones and therefore cause more abomasal lesions. Shorter particles, however, may be sharper and may become stuck in the abomasal wall more easily. Chopping wheat straw to particle sizes equal to those of barley grain lowered lesion incidence to approximately equal levels for the 2 feedstuffs, supporting the theory that longer particles cause more damage, although the severity of the lesions was higher for barley grain (Cozzi et al., 2002b). This implies that both the size and type of feed affect abomasal damage. In contrast, Webb et al. (2013) found no effect of providing roughages in long-chopped, short-chopped, or ground form.

For pelleted feeds, it would be expected that their finer particles would have a lesser traumatizing or blocking effect on the abomasal mucosa or pyloric sphincter, respectively, and thereby cause less damage to the abomasum. However, no difference in abomasal damage was found between straw and straw pellets (Van Putten, 1982), which contradicts this hypothesis. In addi- tion, pelleted maize silage was observed to cause more lesions than short-chopped or ground maize (cob) silage (Wensing et al., 1986; Breukink et al., 1991). Whether this difference is actually due to the pelleted form or to the different roughage types cannot be determined from these studies. Nevertheless, the lack of difference between straw and pelleted straw implies that roughage type is the main determinant here.

Amount of Solid Feed. In addition to type and physical form of roughage, the amount of SF fed may affect abomasal damage. Larger amounts are expected to increase trauma to the abomasal wall and worsen blocking of the pyloric sphincter, thereby increasing abomasal damage. Indeed, larger, but still restricted, amounts of roughage have been shown to increase the prevalence and size of ulcers (Brscic et al., 2011; Webb et al., 2013). However, increasing amounts of cereal grains and straw were not seen to increase lesion incidence (Morisse et al., 1999), which may be linked to the inclusion of concentrate in the diet, as theorized before. In contrast, inclusion of a high level of concentrate (concentrate:roughage 80:20) does increase abomasal damage when the amount fed increases (Berends et al., 2014). For some roughage sources, an interaction between the amount fed and the type of roughage was found, where the source was only severely damaging when fed in larger amounts. For example, maize (cob) silage caused fewer lesions than straw at small amounts $(250 \mathrm{~g} / \mathrm{d})$ and more lesions than straw in larger amounts $(500 \mathrm{~g} / \mathrm{d}$; Webb et al., 2013). A finding that contradicts the hypothesis that larger amounts of SF lead to more abomasal damage is that provision of straw or hay ad libitum does not exacerbate lesions caused by MR (Webb et al., 2013, 2015). We may speculate that ad libitum provision allows the individual calf to select a diet that is quantitatively optimal for its body, including its abomasum. Furthermore, it minimizes competition between pen mates and allows meals throughout the day, likely reducing feeding rate and meal size. Alternatively, rumen development may play a role (see the Rumen Development section). Finally, Prevedello et al. (2012) proposed that the moment at which the $\mathrm{SF}$ is consumed might matter. Consumption of SF immediately after the abomasum has been filled with a large quantity of MR may exacerbate overloading and increase abomasal damage.

\section{Rumen Development}

Before entering the abomasum, SF must pass the 3 other stomach compartments. In the first, the rumen, SF will be fermented. It has been hypothesized that feed will be less coarse when it enters the abomasum if this feed is well fermented (Berends et al., 2012). In 
addition, because of the smaller particle size resulting from good or better fermentation, SF should also block the pylorus less frequently than when fermented incompletely. Because calves are born with a nonfunctional rumen, its development affects the extent to which SF is fermented. Beef calves and lambs are more susceptible to abomasal perforation caused by ulcers during the development from preruminant to ruminant, which normally occurs at approximately 4 to 8 wk of age (Jelinski et al., 1996a; Dirksen et al., 1997; Vatn and Ulvund, 2000). Stimulating rumen fermentation and development at an early age has been proposed as a way of minimizing abomasal damage (Berends et al., 2012). This can be achieved using a feeding regimen aimed at early rumen development (ERD), which includes feeding both roughage and concentrate from an early age onward. An increase in rumen volume and weight is stimulated by the feeding of fibrous feeds, whereas the development of rumen papillae is stimulated by volatile fatty acids and therefore by less fibrous feeds (Berends et al., 2014; Suarez-Mena et al., 2016).

In support of this theory, one study found that calves with better developed rumens had fewer abomasal lesions than calves with less developed rumens (Webb et al., 2013), and others found that stimulating early development with concentrate or hay meant that future feeding of coarse straw did not exacerbate damage (Veissier et al., 1998; Webb et al., 2015). However, when the ERD theory was tested by adjusting calf diet before the age of $12 \mathrm{wk}$, it was found that ERD only decreases the incidence of scars (Berends et al., 2012). These findings suggest that ERD protects calves from developing abomasal ulcers during the early weeks of life, leading to less scarring later on, but that it has no effect on ulcer or erosion development in later life. Two years later, the same authors confirmed that better rumen development does not protect against abomasal damage at a later age (Berends et al., 2014), based on the finding that both rumen development score and abomasal damage increased for increasing SF amounts (when the proportion of concentrate was high).

\section{Hairballs}

Hairballs (or trichobezoars) are round masses composed of ingested hair (Çatik et al., 2015) that develop in the rumen and sometimes in the abomasum (Osborne, 1976). Webb et al. (2013) proposed that ruminal hairballs might prevent proper digestion in the rumen, which would allow large feed particles to pass through the first 3 stomach compartments into the abomasum. These underfermented particles may cause trauma to the abomasal mucosa or block the pyloric exit. Rumen motility, which can be improved by feeding SF in addition to MR, aids in the removal of hair from the rumen, thereby preventing the development of hairballs (Morisse et al., 1999, 2000; Cozzi et al., 2002a). Alternatively, calves fed SF may ingest less hair than calves fed MR only, as they display fewer abnormal oral behaviors (Veissier et al., 1998; Mattiello et al., 2002), during which hair can be ingested. Calves fed straw or hay have less hair in their rumen than calves fed maize (cob) silage, with those fed maize silage being intermediate, and the amount of hair was further reduced as roughage particle size was increased (Webb et al., 2010, 2013). Nevertheless, Webb et al. (2013) found that calves fed only milk had more ruminal hairballs and fewer abomasal lesions than calves fed additional roughage (with the exception of ad libitum hay, for which ulcer incidence was not increased). This implies that ruminal hairballs are at least not a prerequisite for the development of abomasal lesions.

Hairballs can also be found inside the abomasum, although this is only true in veal calves fed only MR. Abomasal hairballs have been hypothesized to cause trauma to the abomasal mucosa or to block the pylorus, both of which may lead to abomasal damage (Jelinski et al., 1996b; Marshall, 2009; Sasaki et al., 2012). Especially during abomasal surgeries performed on suckling calves, large amounts of hair were found in ulcerated or perforated abomasa (Tulleners and Hamilton, 1980; Katchuik, 1992; Çatik et al., 2015). Only one study on veal calves measured the presence of both hairballs and lesions in the abomasum, but a relationship between the two was not evaluated (Osborne, 1976). Studies in beef calves suggest that hairballs do not cause trauma to the abomasal mucosa and do not block the pylorus enough to cause ulceration (Katchuik, 1992; Jelinski et al., 1996b). In lambs, significantly more bezoars were found in lambs with abomasal ulcers than in those without ulcers (Vatn and Ulvund, 2000). Despite these inconclusive results, veterinarians and researchers tend to assume a relationship between hairball presence in the abomasum and abomasal lesions (Stokka and Perino, 2000; Marshall, 2009; Çatik et al., 2015).

\section{Nutrient Deficiencies}

Although it is often suggested that nutrient, most often mineral, deficiencies can cause or facilitate the formation of abomasal ulcers (Jelinski et al., 1996b; Stokka and Perino, 2000; Ahmed et al., 2002; Marshall, 2009; Van Immerseel et al., 2010), only one study on veal calves researched part of this relationship. That study found no effect of iron supplementation on abomasal damage, in calves fed MR only (Webb et al., 2013). When beef calves were supplied with a free-choice mineral mix, a nonsignificant trend for a 
decreased need for abomasal surgery due to ulceration was observed (Katchuik, 1992). This implies a role for nutrient deficiencies in abomasal ulceration (composition of the mineral mix is unknown but can be assumed to differ between the farms the calves originated from). In another study, deficiencies in copper or selenium occurred more often in beef calves with (perforating) abomasal damage (Mills et al., 1990). Supplementation of copper to both cows and their calves immediately decreased the occurrence of ulceration close to zero (Lilley et al., 1985).

It has been theorized that a low serum copper concentration can lead to a derangement of elastin cross-linkages in the abomasal wall, compromising the abomasal mucosa and microvasculature and leaving the abomasal wall prone to damage (Lilley et al., 1985; Marshall, 2009). In addition, copper deficiency can lead to decreased neutrophil function and subsequently to an increased risk of infection, as occurs when the abomasum is damaged (Lilley et al., 1985; Mills et al., 1990; Marshall, 2009). Because a high concentration of zinc, molybdenum, or sulfur reduces the availability of copper, surplus of these minerals can exacerbate the problem of copper shortage. Thus, in beef calves, nutrient deficiencies, at least for copper and selenium, appear to affect abomasal damage. Whether the same occurs in veal calves has not yet been studied.

\section{Water}

Veal calves receive fluids from milk, from other feeds provided, from the drinking of free water, and from the oxidation of food and body tissue. Whereas water originating from feed and free water is deposited in the rumen, water originating from milk generally bypasses the rumen and is deposited in the abomasum (Hepola et al., 2008). Although some studies report that calves fed MR ad libitum drink hardly any water (Hepola et al., 2008), others found that calves may ingest large amounts of up to $36 \mathrm{~L} / \mathrm{d}$, with an average consumption of 11.3 L/d (Ruis-Heutinck and Van Reenen, 2000; Webb et al., 2014). Water intake increases when calves start consuming SF (Kertz et al., 1984) and is higher in calves fed more SF (Webb et al., 2014). Supplying calves with an increasing amount of free water (from 3 to $8 \mathrm{~L} / \mathrm{d}$ ) did not affect abomasal ulcers, erosions, or inflammations (Gottardo et al., 2002). However, one risk assessment showed that calves receiving water ad libitum were at higher risk for lesions than those receiving none at all (Brscic et al., 2011). However, consumption of water was, in that study, strongly linked to the provision of $\mathrm{SF}$ and ruminal plaque, indicating that $\mathrm{SF}$ may have caused the damage in that case.

\section{THE FACTOR OF STRESS}

In many monogastric species, acute stress has been experimentally shown to cause ulceration of the stomach mucosa (rat: Goldman and Rosoff, 1968; Weiner, 1996; guinea pig: Ludwig and Lipkin, 1969; piglet, but not pig: Norton et al., 1972). In ruminants, such as calves, the abomasum acts similarly to the monogastric stomach. In some cases, the stress-induced lesions of monogastrics resemble the ulcers found in the calf fundus (Welchman and Baust, 1987). Therefore, many authors have noted that stress may be a predisposing or even causal factor for ulceration in calves as well (Tulleners and Hamilton, 1980; Lourens et al., 1985; Wiepkema, 1985; Welchman and Baust, 1987; Wiepkema et al., 1987; Breukink et al., 1989; Mills et al., 1990; Lallès and Toullec, 1998; Stokka and Perino, 2000; Ahmed et al., 2002; Constable et al., 2005; Marshall, 2009; Van Immerseel et al., 2010; Sasaki et al., 2012; Valgaeren et al., 2013; Webb et al., 2013; Berends et al., 2014; Çatik et al., 2015). Proposed pathways through which stress could cause abomasal damage have a common starting point, whose involvement has been demonstrated only in rats. In rats, ulcers caused by stress only develop after a drop in body temperature (Weiner, 1996), which initiates 2 main pathways: (1) increased production of gastric acids, whose effects were described previously (see section titled Low Abomasal pH); and (2) a decrease in the rhythm of stomach contractions from 6 to 7 to only 0.5 to 2 times per minute, which leads to decreased mucosal blood flow and subsequent damage through local hypoxia, mechanical damage, and decreased function of the mucosa-protecting mucus and cytoprotective prostaglandins (Weiner, 1996; Marshall, 2009; Kureljušić et al., 2013).

It has been proposed that abomasal ulcers in veal calves are not related to stress, because the location of these ulcers is not similar to that of ulcers caused by stress in adult cattle (Breukink et al., 1991). In veal calves, ulcers are predominantly found in the pyloric region, whereas in adult cattle they are predominantly found in the fundic region. It is unclear what this assumption of stress being a causal factor in adult cattle is based on. Bähler et al. (2010) found that calves in conventional veal systems had more fundic but not pyloric lesions than animals kept in a potentially less stressful system in which they had more square meters per individual, could go outdoors and received water and roughage ad libitum. Bähler et al. (2010) proposed, therefore, that stress might be involved in the development of fundic but not pyloric lesions. In that study, however, diet was also an important difference between these 2 rearing systems. Other studies did not 
identify links between stress and abomasal damage in veal calves, regardless of the treatments that were used: individual housing versus group housing (Veissier et al., 1997; Bokkers and Koene, 2001), repeated regrouping (Veissier et al., 2001), or environmental enrichment (Veissier et al., 1997). Furthermore, calves used to human-calf interactions (gentled calves), which involved the stockperson talking to and stroking the calves and letting the calf suck the person's fingers for $90 \mathrm{~s}$ following feeding, had fewer pyloric lesions at slaughter (Lensink et al., 2000). Because the human-calf interaction allowed calves to suck on the stockperson's fingers, enhanced saliva production might also have decreased abomasal acidity and consequently ulceration. In that case, the difference found would be unrelated to stress, as also suggested by the absence of differences in stress measurements (behavioral observations, response to ACTH challenge) between gentled and control calves.

Calves performing more of the abnormal oral behavior tongue rolling or playing were found to have significantly fewer abomasal ulcers and scars but not fewer erosions (Wiepkema et al., 1987). In addition, in a more recent study, the same relationship was found between abomasal lesions and tongue playing as well as oral manipulation of the environment (Webb, 2014). Stereotypies, such as these abnormal oral behaviors, are defined as repetitive and invariant behavioral patterns that lack an obvious goal or function (Rushen and Mason, 2006), and they may provide captive animals with a way to cope with a suboptimal environment (Würbel et al., 2006). Calves that tongue roll may develop less abomasal damage due to reduced stress through better coping. Similarly, rats that were exposed to acute stress, in the form of electric shocks, developed more gastric ulcers when punished for attempting to escape these shocks, which denies the rats a way to cope with the acute stress (Weiner, 1996). Other mechanisms might be that extra saliva produced when performing abnormal oral behaviors would increase abomasal $\mathrm{pH}$, although it could be argued that saliva produced during object manipulation may not enter the gastrointestinal tract, or that increased satisfaction of oral eating behaviors decreased milk intake and thereby abomasal overloading.

\section{FACTORS ASSOCIATED WITH DISEASE}

\section{Microorganisms}

Infections caused by fungi, bacteria, parasites, and diseases caused by viruses are hypothesized to lead to the development of abomasal damage in calves (Ross, 1963; Smith, 1966; Stokka and Perino, 2000; Marshall,
2009; Moeller et al., 2013); see Tables 2, 3, 4, and 5 for an overview of these studies. This hypothesis is partly because microorganisms are known to cause peptic ulcers in humans (Overmier and Murison, 2013). In calves, fungi have been isolated from abomasal lesions but evidence for a causal role is currently insufficient (Table 2). Studies investigating bacterial involvement are more abundant; however, bacteria isolated from lesions may originate from postmortem colonization. Additionally, administration of bacteria leads to a different type of damage than is commonly observed in veal calves; namely, numerous small ulcers spread throughout the abomasum (Table 3). Furthermore, although some parasites are capable of causing ulcers in calves (Ross, 1963; Ross and Dow, 1965; Snider et al., 1981, 1985; Taylor et al., 1989; Yang et al., 1993), cattle (Snider et al., 1985), and elk (Woodbury and Parry, 2009), it is unlikely and not reported that indoor-housed calves, fed on concentrate and silages, are exposed to these parasites. Moreover, the type of abomasal damage caused by parasites, referred to as nodules, is quite different from that described most commonly in veal calves (Table 4). Finally, although some viruses can cause lesions in several organs (including the abomasum) in dairy calves (Moeller et al., 2013), beef calves (Bianchi et al., 2017), and adult cattle (Assis et al., 2002 ), the prevalence of viral diseases is much lower than the prevalence of abomasal damage ( $2 \%$ compared with $>70 \%$; Brscic et al., 2011; Bianchi et al., 2017). Viruses, although possibly causing some of the cases of abomasal damage found in veal calves (Table 5), are unlikely to be a main factor in the majority of damage found. However, given the small amount of research in this area, we encourage further focus on this area. Noninfectious diseases, left abomasal displacement, and certain types of tumors might also cause abomasal ulcers in adult cattle and, in very rare cases, calves (Smith et al., 1983; Mueller et al., 1999; Sasaki et al., 2012) but are deemed irrelevant in veal calves.

\section{Medication}

Veal calves in Europe (Belgium and the Netherlands) have been reported to be the group of farm animals receiving the most antimicrobial (AM) treatments (Bondt et al., 2012; Pardon et al., 2012b), likely as a direct consequence of the mixing of young, low-immunity calves from many different origins. In Belgium, over $40 \%$ of calves were treated with AM every day of the production cycle (Pardon et al., 2012b). Although much less frequently used than AM drugs, (non)steroidal anti-inflammatory drugs [(N)SAID] are also given to veal calves; of all treatments in Belgian veal calves 
in 2009, $88 \%$ was AM and $12 \%$ was NSAID (Pardon et al., 2012b). Compared with the $40 \%$ use of AM drugs, NSAID were given to $0.6 \%$ of veal calves per day of production in Belgium (Pardon et al., 2012b). Most NSAID are likely given as part of the treatment for respiratory diseases, similar to AM drugs (Pardon et al., 2012b). Ibuprofen (Walsh et al., 2016) and other NSAID (Semrad and Dubielzig, 1994; Sasaki et al., 2012) have been found to cause abomasal lesions in calves. Additionally, NSAID are a known cause of peptic ulcers in humans (Yeomans and Næsdal, 2008). Medication is widely used in veal calves and could be an important factor in the development of abomasal damage; however, the current evidence for this is nonexistent and future research is warranted. Nonetheless, the use of NSAID lies far below the prevalence of abomasal damage in veal calves and is unlikely to be one of the main factors.

\section{OTHER FACTORS}

\section{Breed}

It has been proposed by some authors that the breed of calf may affect abomasal damage. For example, Montbéliarde calves develop more pyloric scars than Holstein Friesian calves when kept in similar systems (Veissier et al., 1997). However, it should be noted that Montbéliarde calves are also capable of growing faster, which is accompanied by a higher MR and SF intake, and thus possibly more severe overloading of the abomasum. This was confirmed by both Bähler et al. (2010) and Brscic et al. (2011), who found no effect of breed on pyloric lesions although, in these studies, breeds were categorized in 3 groups (dairy breeds, cross-breeds, and other breeds) and only those groups were compared, not individual breeds. Breed might have an important impact on abomasal lesions when a particular breed is able to consume more $\mathrm{MR}$ and $\mathrm{SF}$ more rapidly.

\section{Seasonal Effects}

In adult cattle and in beef cattle, occurrence of abomasal damage differs between seasons. In adult dairy cattle, this could be related to the seasonality of milk production, because most ulcers develop around parturition, a period marked by stress and a severe change in diet (Smith et al., 1983; Sanford and Josephson, 1988; Ok et al., 2001; Tharwat and Ahmed, 2012). In beef calves, bad weather has often been proposed as a contributing factor (Jensen et al., 1976; Lilley et al., 1985; Mills et al., 1990; Marshall, 2009). It is theorized that calves do not nurse when the weather is bad, which leads to a drop in abomasal $\mathrm{pH}$, leaving the abomasum vulnerable to ulceration. When the weather is better, calves overconsume milk, which leads to abomasal overloading. In one study, the seasonal effect was fully explained by the use of a seasonal beef production system, indicating that other season-related effects, such as pasture growth, were not causal (Jelinski et al., 1996a).

Because veal calves originate mostly from a nonseasonal dairy system, are kept inside, and do not nurse their dams, bad weather should not have an effect on abomasal damage. Nevertheless, a risk assessment conducted by Brscic et al. (2011) showed that veal calves have a higher risk of developing pyloric lesions when they are raised in the summer or autumn and the lowest risk when reared in spring, both compared with winter. Why this effect exists is unknown. We may speculate that it correlates with other (as yet unidentified) factors that differ seasonally or that differences in living conditions between seasons on the dairy farm of origin have a predisposing effect. Temperature fluctuations in the stable, which can occur if temperature is not regulated year round, might have an effect; for example, through cold or heat stress. As mentioned before, fluctuations in body temperature of rats can lead to the development of stomach ulcers (Weiner, 1996). Alternatively, calves may be fed more or ingest feed faster in certain seasons.

Table 2. Evidence for the role of fungi in the etiology of abomasal damage in calves

\begin{tabular}{|c|c|c|c|c|c|}
\hline Study conclusion & $\begin{array}{l}\text { Lesion } \\
\text { type }\end{array}$ & $\begin{array}{l}\text { Fungus } \\
\text { species }\end{array}$ & $\begin{array}{l}\text { No. of } \\
\text { calves }\end{array}$ & Reference & $\begin{array}{l}\text { Study } \\
\text { type }^{1}\end{array}$ \\
\hline Isolation of fungal hyphae from damage & $\begin{array}{l}\text { Numerous } \\
\text { ulcers, edema }\end{array}$ & Not identified & $3 / 5$ & $\begin{array}{l}\text { Wray and Thomlinson, } \\
1968\end{array}$ & $\mathrm{O}$ \\
\hline Isolation of fungal hyphae from damage & Ulcers & $\begin{array}{l}\text { Absidia remosa } \\
\text { Absidia corymbifera } \\
\text { Mucor pusillus }\end{array}$ & 7 & $\begin{array}{l}\text { Gitter and Austwick, } \\
1957\end{array}$ & $\mathrm{O}$ \\
\hline
\end{tabular}

${ }^{1}$ Observational. 
INVITED REVIEW: ABOMASAL DAMAGE IN VEAL CALVES

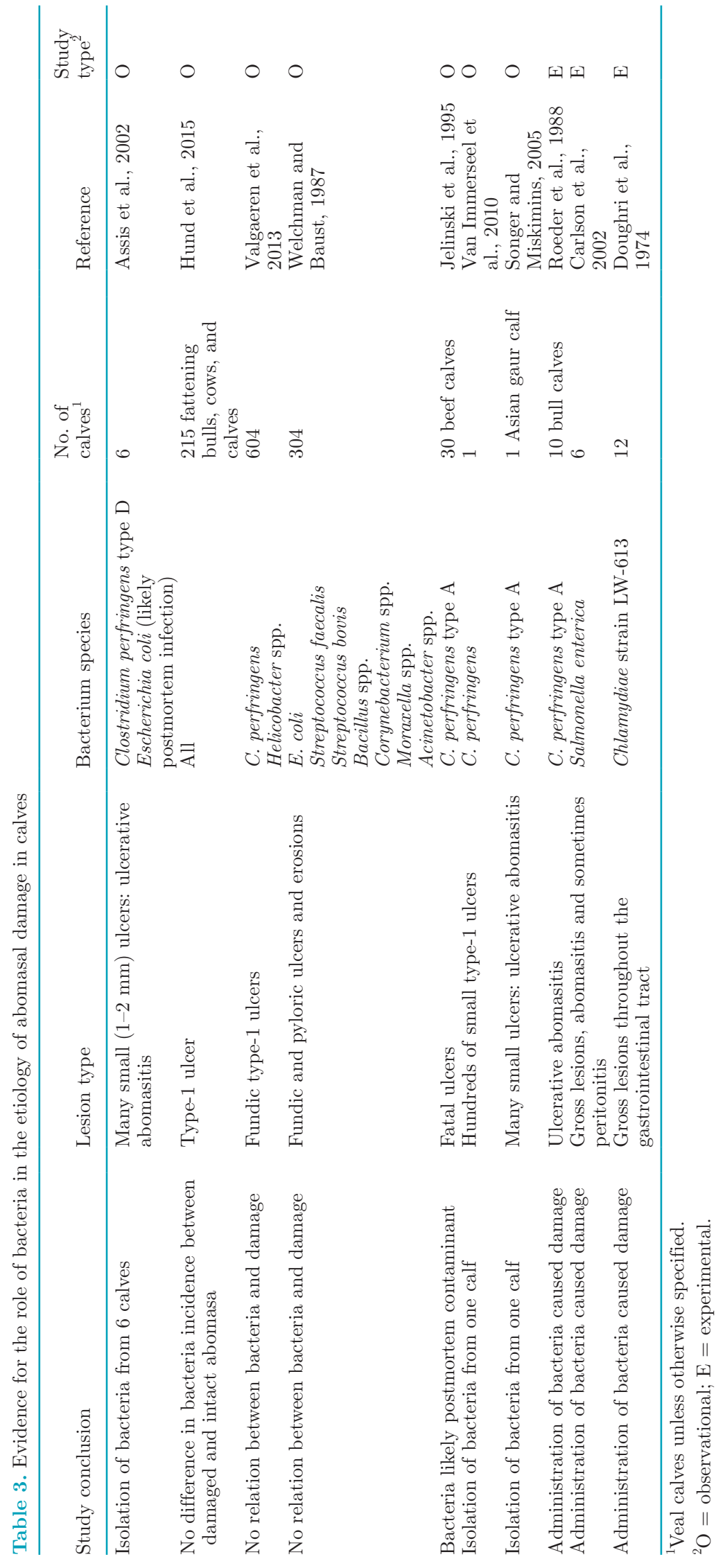


BUS ET AL.
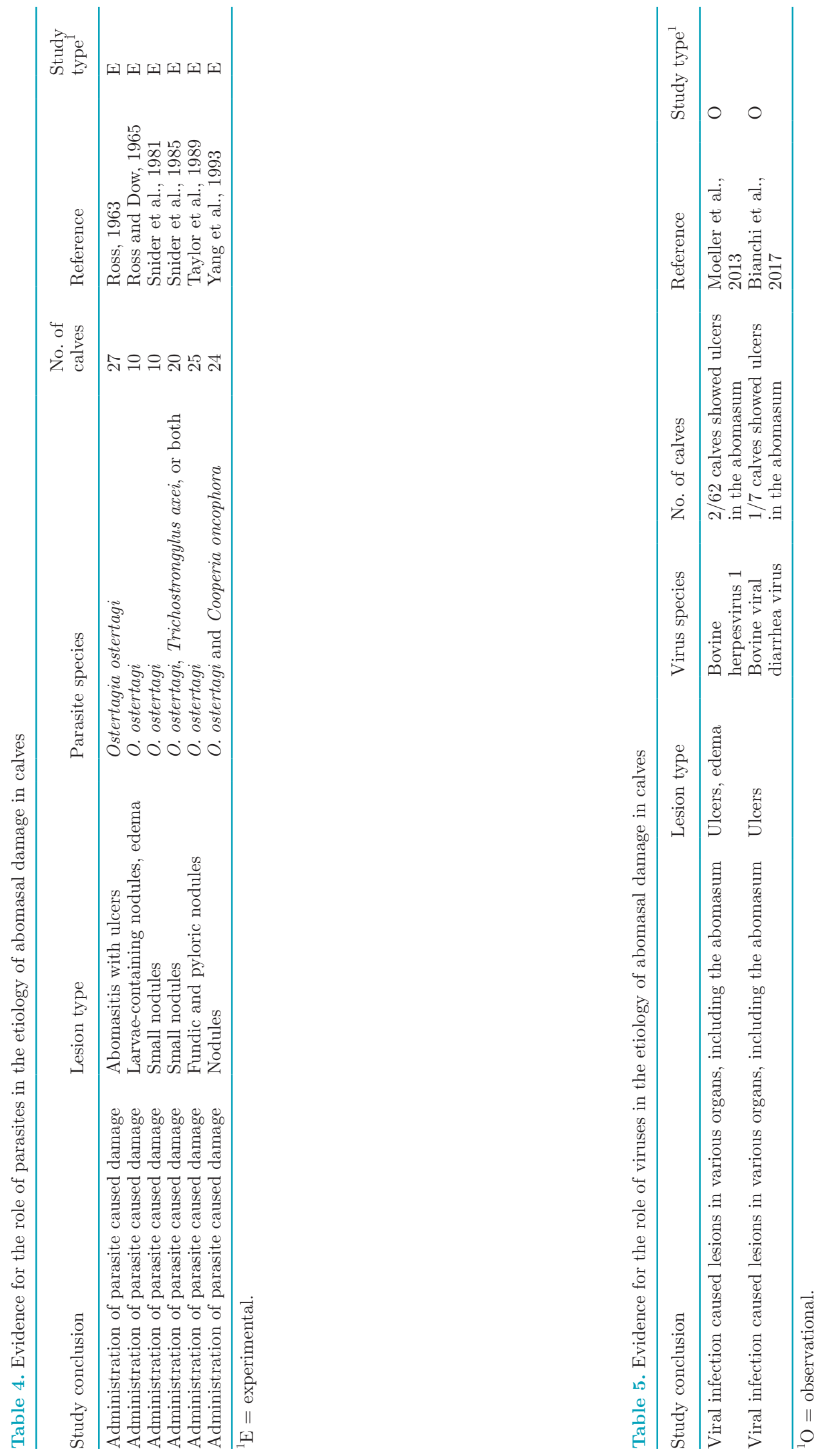


\section{Housing and Management}

Certain aspects of housing and management have also been associated with lesion prevalence via surveys. Absence of a heating system and regular visits of a veterinarian appear to be linked to the occurrence of pyloric lesions (Brscic et al., 2011). Calves living in a stable with an open-front building had fewer pyloric lesions than those in stables with manual ventilation (Bähler et al., 2010). It is unlikely that these factors have a direct effect on abomasal lesions; instead, they likely correlate with other factors that do have a direct effect, such as stress or fluctuations in temperature.

\section{Individual Susceptibility}

Finally, it has been proposed that calves differ in individual susceptibility to abomasal lesions, because calves kept in similar systems, either on the same or on another farm, can show very different degrees of abomasal lesion. This is also observed within pens (Wensing et al., 1986; Wiepkema et al., 1987), although contradictory findings exist (Räber et al., 2013b). Where some calves show severe ulceration, other calves kept under the same conditions may have completely undamaged abomasa. Thus, calves are not equally susceptible to abomasal ulceration (Welchman and Baust, 1987), possibly because of the different mechanisms with which calves cope with stress (and stress is likely associated with fundic lesions). In addition, faster-growing calves are more susceptible to damage (Bähler et al., 2010), although this was not seen in fattening bulls, in which carcass weight and fat distribution were not found to affect abomasal ulceration (Hund et al., 2016). This implies that the difference is not due to individual susceptibility but perhaps to more abomasal overloading in faster-growing calves. It has been suggested that only by offering calves free choice of diet can an appropriate

Table 6. Overview of current knowledge on all proposed risk factors of abomasal damage in veal calves, with associated number of studies in support (for) or not in support (against) of these proposed factors ${ }^{1}$

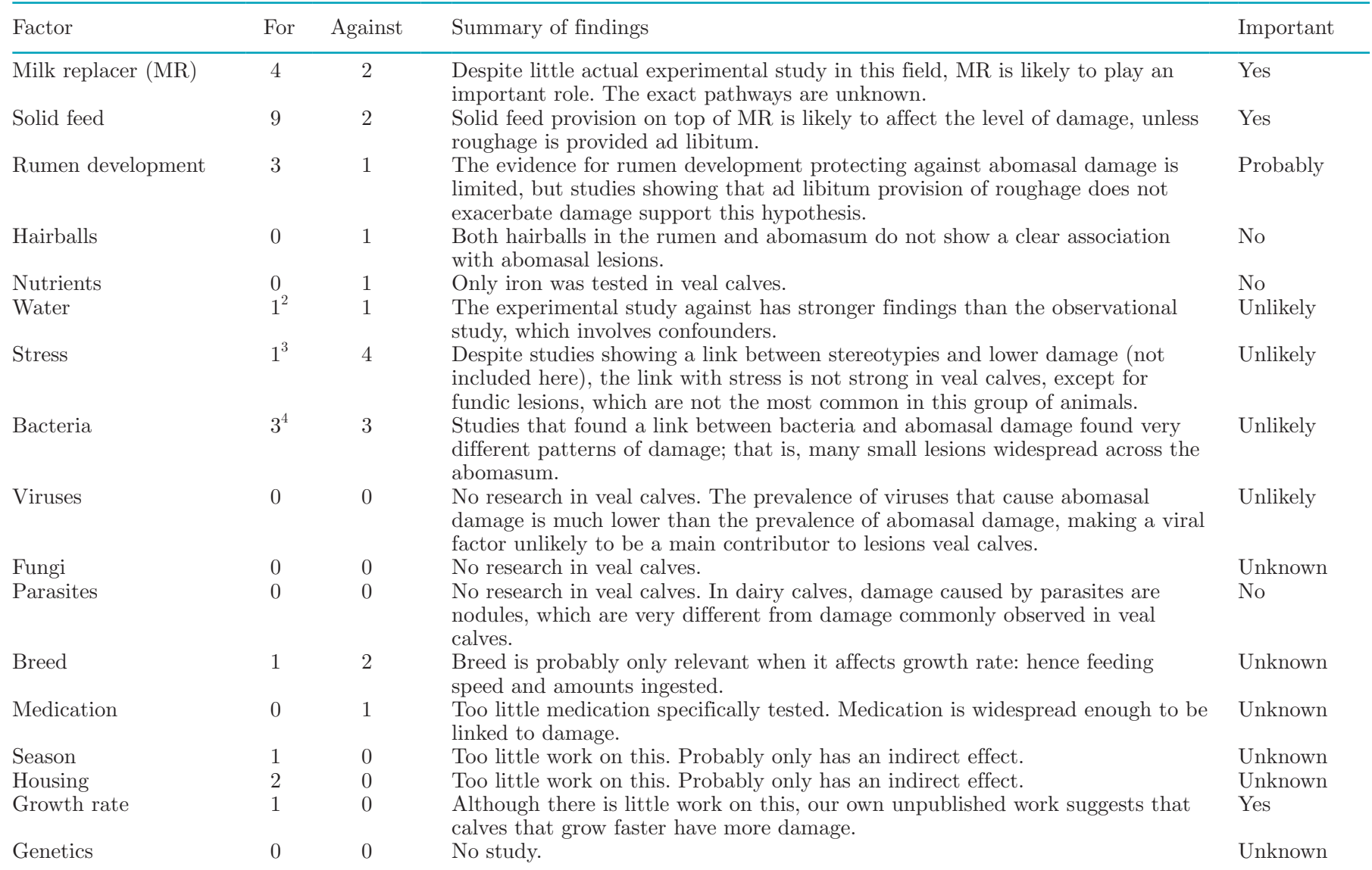

${ }^{1}$ Only studies specifically studying veal calves are included here.

${ }^{2}$ A cross-country survey by Brscic et al. (2011), where water provision was correlated with solid feed provision.

${ }^{3}$ Substantial confounding factor of nutrition (Bähler et al., 2010).

${ }^{4}$ Two of these studies found damage very different from that commonly found in veal calf abomasa. 
diet be provided for each individual calf (Webb et al., 2014).

In humans, stomach ulcers are thought to have a heritable component (Holle, 2010). Whether this is the case in calves has, to our knowledge, never been studied. Nevertheless, if abomasal damage in calves indeed has a heritable component, the application of this finding is likely limited, because veal calves originate from the dairy sector, in which other breeding factors are important.

\section{SUMMARY AND CONCLUSIONS}

The aim of this review was to integrate the information currently available on the etiology of, and risk factors for, abomasal damage in the form of ulcers, erosions, and scars. Some information may have been excluded because it was in a (for us) foreign language (articles included were in Dutch or English). In addition, extrapolation of results from the older literature may not be fully accurate, because the growing systems in which veal calves are kept have changed substantially over time. Nevertheless, experimental studies from earlier periods can still provide useful information. An overview of all proposed factors and associated litera- ture support or evidence is presented in Table 6. An overview of the most likely factors and the associated mechanisms is presented in Figure 1. Although a clear effect on the development of abomasal damage was not identified for all proposed factors, it is clear that the etiology is multifactorial, with various dietary factors contributing to pyloric lesion formation extensively and fundic lesions probably being linked to stress. Pyloric lesion incidence can likely be reduced by feeding smaller quantities of milk replacer in more frequent meals that, from an early age, should be combined with SF in the form of both concentrate and roughages. In addition, decreasing the level of stress experienced by veal calves may decrease the occurrence of fundic lesions and improve overall animal welfare by minimizing negative experiences.

In future research, pyloric and fundic lesions, as well as lesion types (i.e., ulcer types 1-4, erosions, or scars), should be scored separately. More research is required to understand the precise pathways by which MR causes such a high prevalence of abomasal lesions in veal calves. Further research is also warranted on the effect of rapid intake of MR and SF caused by restricted amounts, competition, and breed. More research is needed on the impact of medication, the chemical composition of the

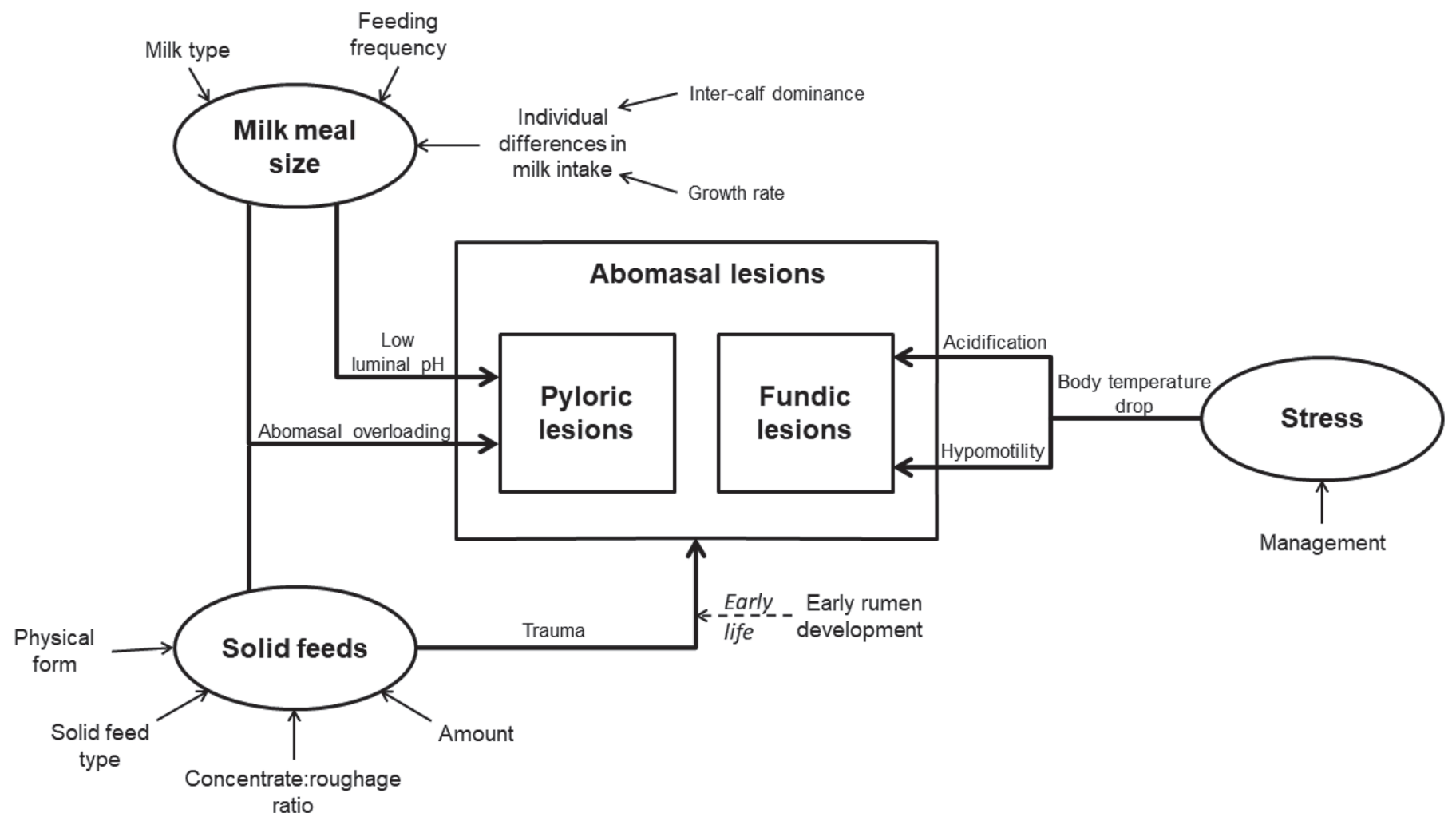

Figure 1. Schematic overview of the most likely risk factors for abomasal damage and the pathways through which these operate. Early rumen development can mitigate trauma, at least during early life. 
MR, and into deficiencies of other nutrients than iron, especially copper and selenium. Finally, no studies have yet focused on the effects of the abomasal emptying rate on abomasal damage; in adult cattle, delayed abomasal emptying has been proposed as a risk (Constable et al., 2006) and in humans, peptic ulcer disease has been associated with delayed gastric emptying (Minami and McCallum, 1984). Another important path of research would be to develop a method that can assess abomasal damage antemortem. Currently, calves must be killed to assess and measure the extent of abomasal damage, which limits the experimental design options. The finding that calves that grow fastest develop most abomasal lesions (Bähler et al., 2010) could be used for this purpose. Finally, the link between abomasal damage and animal welfare, or more specifically pain, is not well understood and has received no research attention to our knowledge. Whether these lesions are painful, and if so, which types are painful and how severe the pain is, is of crucial importance because this health problem is widespread in the veal industry. One complication here is that commonly used indicators of pain in calves, such as growth rate and feeding rate, are linked to the etiology of the problem at hand. Other indicators of pain (e.g., facial expressions) will have to be investigated.

\section{ACKNOWLEDGMENTS}

This paper is the result of a stimulating discussion at the 50th Congress of the International Society for Applied Ethology, held in Edinburgh in 2016. We thank all the lovely people involved in this discussion on abomasal damage in calves: Margit Bak Jensen (Aarhus University, Denmark), Anne Marie de Passillé and Jeff Rushen (University of British Columbia, Canada), Eddie Bokkers and Kees van Reenen (Wageningen University and Research, the Netherlands), Laura Hänninen (University of Helsinki, Finland), and Derek Haley (University of Guelph, Canada).

\section{REFERENCES}

Ahmed, A. F., P. D. Constable, and N. A. Misk. 2002. Effect of feeding frequency and route of administration on abomasal luminal $\mathrm{pH}$ in dairy calves fed milk replacer. J. Dairy Sci. 85:1502-1508. https:/ /doi.org/10.3168/jds.S0022-0302(02)74219-7.

Assis, R. A., F. C. F. Lobato, E. J. Facury Filho, F. A. Uzal, F. J. F. Santana, L. D. Dias, and M. Parreiras. 2002. Isolation of Clostridium perfringens type D from a suckling calve with ulcerative abomasitis. Arch. Med. Vet. 34:287-292. https://doi.org/10.4067/ S0301-732X2002000200015.

Bähler, C., G. Regula, M. H. Stoffel, A. Steiner, and A. Von Rotz. 2010. Effects of the two production programs "Naturafarm" and "conventional" on the prevalence of non-perforating abomasal lesions in Swiss veal calves at slaughter. Res. Vet. Sci. 88:352-360. https://doi.org/10.1016/j.rvsc.2009.08.009.
Bähler, C., A. Steiner, A. Luginbühl, A. Ewy, H. Posthaus, D. Strabel, T. Kaufmann, and G. Regula. 2012. Risk factors for death and unwanted early slaughter in Swiss veal calves kept at a specific animal welfare standard. Res. Vet. Sci. 92:162-168.

Berends, H., J. J. G. C. Van den Borne, H. Mollenhorst, C. G. Van Reenen, E. A. M. Bokkers, and W. J. J. Gerrits. 2014. Utilization of roughages and concentrates relative to that of milk replacer increases strongly with age in veal calves. J. Dairy Sci. 97:6475-6484. https://doi.org/10.3168/jds.2014-8098.

Berends, H., C. G. Van Reenen, N. Stockhofe-Zurwieden, and W. J. J. Gerrits. 2012. Effects of early rumen development and solid feed composition on growth performance and abomasal health in veal calves. J. Dairy Sci. 95:3190-3199. https://doi.org/10.3168/ jds.2011-4643.

Bianchi, M. V., G. Konradt, S. O. De Souza, D. M. Bassuino, S. Silveira, A. C. S. Mósena, C. W. Canal, S. P. Pavarini, and D. Driemeier. 2017. Natural outbreak of BVDV-1d-induced mucosal disease lacking intestinal lesions. Vet. Pathol. 54:242-248. https:// doi.org/10.1177/0300985816666610.

Blokhuis, H. J. 2000. Chain management of veal calf welfare. Final report EU-project contract number FAIR 3 PL96-2049. ID-Lelystad, Lelystad, the Netherlands.

Bokkers, E. A. M., and P. Koene. 2001. Activity, oral behaviour and slaughter data as welfare indicators in veal calves: A comparison of three housing systems. Appl. Anim. Behav. Sci. 75:1-15. https: //doi.org/10.1016/S0168-1591(01)00175-7.

Bondt, N., L. Puister, L. Ge, H. van der Veen, R. Bergevoet, B. Bouma, A. van Vliet, and K. Wehling. 2012. MARAN-Trends in veterinary antibiotic use in the Netherlands 2004-2012. LEI, Wageningen UR, Wageningen, Netherlands.

Breukink, H. J., T. Wensing, and J. M. V. M. Mouwen. 1991. Abomasal ulcers in veal calves: Pathogenesis and prevention. Pages 118-122 in New Trends in Veal Calf Production - Proc. Int. Symp. Veal Calf Production, Wageningen, Netherlands. J. H. M. Metz and C. M. Groenestein, ed. Pudoc Wageningen, the Hague, the Netherlands.

Breukink, H. J., T. Wensing, S. Van Dijk, and D. Mevius. 1989. Effect of clenbuterol on the incidence of abomasal lesions in veal calves. Vet. Rec. 125:109-111.

Brscic, M., L. F. M. Heutinck, M. Wolthuis-Fillerup, N. Stockhofe, B. Engel, E. K. Visser, F. Gottardo, E. A. M. Bokkers, B. J. Lensink, G. Cozzi, and C. G. Van Reenen. 2011. Prevalence of gastrointestinal disorders recorded at postmortem inspection in white veal calves and associated risk factors. J. Dairy Sci. 94:853-863. https: //doi.org/10.3168/jds.2010-3480.

Brscic, M., P. Prevedello, A. L. Stefani, G. Cozzi, and F. Gottardo. 2014. Effects of the provision of solid feeds enriched with protein or nonprotein nitrogen on veal calf growth, welfare, and slaughter performance. J. Dairy Sci. 97:4649-4657. https://doi.org/10.3168/ jds.2013-7618.

Carlson, S. A., W. C. Stoffregen, and S. R. Bolin. 2002. Abomasitis associated with multiple antibiotic resistant Salmonella enterica serotype Typhimurium phagetype DT104. Vet. Microbiol. 85:233240. https://doi.org/10.1016/S0378-1135(01)00508-9.

Çatik, S., M. Akbala, H. Kurt, and H. Salci. 2015. Abomasal ulcer and jejunal ileus caused by trichobezoar in a two-day-old calf. Ankara Univ. Vet. Fak. Derg. 62:139-145.

Constable, P. D., A. F. Ahmed, and N. A. Misk. 2005. Effect of suckling cow's milk or milk replacer on abomasal luminal $\mathrm{pH}$ in dairy calves. J. Vet. Intern. Med. 19:97-102. https://doi.org/10.1111/j .1939-1676.2005.tb02665.x.

Constable, P. D., T. Wittek, A. F. Ahmed, T. S. Marshall, I. Sen, and M. Nouri. 2006. Abomasal pH and emptying rate in the calf and dairy cow and the effect of commonly administered therapeutic agents. Proc. World Buiatrics Congr., Nice, France. https://pdfs.semanticscholar.org/a9c0/ 680c90fa2f8e85a5027eb5add113cfd9a880.pdf.

Cozzi, G., M. Brscic, and F. Gottardo. 2010. Main critical factors affecting the welfare of beef cattle and veal calves raised under intensive rearing systems in Italy: A review. Ital. J. Anim. Sci. 8:67-80. https://doi.org/10.4081/ijas.2009.s1.67. 
Cozzi, G., F. Gottardo, S. Mattiello, E. Canali, E. Scanziani, M. Verga, and I. Andrighetto. 2002a. The provision of solid feeds to veal calves: I. Growth performance, forestomach development, and carcass and meat quality. J. Anim. Sci. 80:357-366. https://doi.org/ $10.2527 / 2002.802357 x$.

Cozzi, G., F. Gottardo, F. Mutinelli, B. Contiero, G. Fregolent, S. Segato, and I. Andrighetto. 2002b. Growth performance, behaviour, forestomach development and meat quality of veal calves provided with barley grain or ground wheat straw for welfare purpose. Ital. J. Anim. Sci. 1:113-126. https://doi.org/10.4081/ijas.2002.113.

De Wilt, J. G. G. 1985. Behaviour and welfare of veal calves in relation to husbandry systems. PhD Thesis. Wageningen University, Wageningen, the Netherlands.

Dirksen, G., K. Doll, J. Einhellig, A. Seitz, G. Rademacher, W. Breitner, and W. Klee. 1997. Abomasal ulcers in calves: Clinical investigations and experiences. Tierarztl. Prax. 25:318-328.

Doughri, A. M., S. Young, and J. Storz. 1974. Pathological changes in intestinal chlamydial infection of newborn calves. Am. J. Vet. Res. 35:939-944.

Gitter, M., and P. K. C. Austwick. 1957. The presence of fungi in abomasal ulcers of young calves: A report of seven cases. Vet. Rec. 69:924-927.

Goldman, H., and C. B. Rosoff. 1968. Pathogenesis of acute gastric stress ulcers. Am. J. Pathol. 52:227-244.

Gottardo, F., S. Mattiello, G. Cozzi, E. Canali, E. Scanziani, L. Ravarotto, V. Ferrante, M. Verga, and I. Andrighetto. 2002. The provision of drinking water to veal calves for welfare purposes. J. Anim. Sci. 80:2362-2372. https://doi.org/10.2527/2002.8092362x.

Guilloteau, P., R. Zabielski, and J. W. Blum. 2009. Gastrointestinal tract and digestion in the young ruminant: Ontogenesis, adaptations, consequences and manipulations. J. Physiol. Pharmacol. 60:37-46.

Haigh, J. C. 1982. Cimetidine for the treatment of abomasal ulcers in young ruminants. J. Zoo Anim. Med. 13:173.

Hepola, H. P., L. T. Hänninen, S. M. Raussi, P. A. Pursiainen, A.-M. Aarnikoivu, and H. S. Saloniemi. 2008. Effects of providing water from a bucket or a nipple on the performance and behavior of calves fed ad libitum volumes of acidified milk replacer. J. Dairy Sci. 91:1486-1496. https://doi.org/10.3168/jds.2007-0500.

Hill, T. M., H. G. Bateman, J. M. Aldrich, J. D. Quigley, and R. L. Schlotterbeck. 2013. Evaluation of ad libitum acidified milk replacer programs for dairy calves. J. Dairy Sci. 96:3153-3162. https: //doi.org/10.3168/jds.2012-6132.

Holle, G. E. 2010. Pathophysioogy and modern treatment of ulcer disease. Int. J. Mol. Med. 25:483-491. (Review). https://doi.org/ 10.3892/ijmm_00000368.

Hund, A., T. Beer, and T. Wittek. 2016. Abomasal ulcers in slaughtered cattle in Austria. Tierarztl. Prax. Ausg. G Grosstiere Nutztiere 44:279-285.

Hund, A., M. Dzieciol, S. Schmitz-Esser, and T. Wittek. 2015. Characterization of mucosa-associated bacterial communities in abomasal ulcers by pyrosequencing. Vet. Microbiol. 177:132-141. https://doi .org/10.1016/j.vetmic.2015.02.023.

Jelinski, M. D., C. S. Ribble, J. R. Campbell, and E. D. Janzen. 1996a. Descriptive epidemiology of fatal abomasal ulcers in Canadian beef calves. Prev. Vet. Med. 26:9-15. https://doi.org/10 1016/0167-5877(95)00500-5.

Jelinski, M. D., C. S. Ribble, J. R. Campbell, and E. D. Janzen. 1996b. Investigating the relationship between abomasal hairballs and perforating abomasal ulcers in unweaned beef calves. Can. Vet. J. 37:23-26.

Jelinski, M. D., C. S. Ribble, M. Chirino-Trejo, E. G. Clark, and E. D. Janzen. 1995. The relationship between the presence of Helicobacter pylori, Clostridium perfringens type A, Campylobacter spp., or fungi and fatal abomasal ulcers in unweaned beef calves. Can. Vet. J. 36:379-382.

Jensen, R., R. E. Pierson, P. M. Braddy, D. A. Saari, A. Benitez, L. H. Lauerman, D. P. Horton, and A. E. McChesney. 1976. Fetal abomasal ulcers in yearling feedlot cattle. J. Am. Vet. Med. Assoc. 169:524-526
Jensen, R., T. R. Spraker, R. D. Glock, R. L. Jones, J. K. Collins, D. E. Flack, R. Kerschen, and R. L. Hoff. 1992. Abomasal erosions in feedlot cattle. Am. J. Vet. Res. 53:110-115.

Katchuik, R. 1992. Abomasal disease in young beef calves: Surgical findings and management factors. Can. Vet. J. 33:459-461.

Kertz, A. F., L. F. Reutzel, and J. H. Mahoney. 1984. Ad libitum water intake by neonatal calves and its relationship to calf starter intake, weight gain, feces score, and season. J. Dairy Sci. 67:29642969. https://doi.org/10.3168/jds.S0022-0302(84)81660-4.

Kureljušić, B., V. Ivetić, B. Savić, N. Jezdimirović, D. Cvetojević, J. Kureljušić, Ž. Ilić, S. Stanojević, and M. Stevančević. 2013. Pathomorphological characteristics of abomasal ulcers in high-yielding dairy cows. Acta Vet. Brno 63:237-246.

Lallès, J. P., and R. Toullec. 1998. Some aspects of nutrition and health in preruminant calves. Pages 113-123 in Production Diseases in Farm Animals. T. Wensing, ed. Wageningen Pers, Wageningen, the Netherlands.

Lawhon, S. D., W. V. Corapi, A. R. Hoffmann, M. C. Libal, E. Alvarez, J. Guarro, B. L. Wickes, J. Fu, E. H. Thompson, and D. A. Sutton. 2012. In utero infection of a calf by Saksenaea erythrospora resulting in neonatal abomasitis and dermatitis. J. Vet. Diagn. Invest. 24:990-993. https://doi.org/10.1177/1040638712452106.

Lensink, B. J., X. Fernandez, X. Boivin, P. Pradel, P. Le Neindre, and I. Veissier. 2000. The impact of gentle contacts on ease of handling, welfare, and growth of calves and on quality of veal meat. J. Anim. Sci. 78:1219-1226. https://doi.org/10.2527/2000.7851219x.

Lilley, C. W., D. W. Hamar, M. Gerlach, and J. L. Johnson. 1985 Linking copper and bacteria with abomasal ulcers in beef calves. Vet. Med. 10:85-88.

Lourens, J. M., J. F. Van der Wal, and J. M. V. Mouwen. 1985. De maagslijmvliesbarrière en het alcus abomasi bij het mestkalf. Tijdschr. Diergeneeskd. 110:755-761.

Ludwig, W. M., and M. Lipkin. 1969. Biochemical and cytological alterations in gastric mucosa of guinea pigs under restraint stress. Gastroenterology 56:895-902. https://doi.org/10.1016/S0016 $-5085(69) 80094-6$.

Marshall, T. S. 2009. Abomasal ulceration and tympany of calves. Vet. Clin. North Am. Food Anim. Pract. 25:209-220. https://doi.org/ 10.1016/j.cvfa.2008.10.010.

Maton, P. N., and M. E. Burton. 1999. Antacids revisited. Drugs $57: 855-870$.

Mattiello, S., E. Canali, V. Ferrante, M. Caniatti, F. Gottardo, G. Cozzi, I. Andrighetto, and M. Verga. 2002. The provision of solid feeds to veal calves: II. Behavior, physiology, and abomasal damage. J. Anim. Sci. 80:367-375. https://doi.org/10.2527/2002 $.802367 \mathrm{x}$.

Mesarič, M., T. Zadnik, and M. Klinkon. 2002. Comparison of serum pepsinogen activity between enzootic bovine leukosis (EBL) positive beef cattle and cows with abomasal ulcers. Slov. Vet. Res. $39: 227-232$.

Mills, K. W., J. L. Johnson, R. L. Jensen, L. F. Woodard, and A. R. Doster. 1990. Laboratory findings associated with abomasal ulcers/tympany in range calves. J. Vet. Diagn. Invest. 2:208-212. https://doi.org/10.1177/104063879000200310.

Minami, H., and R. W. McCallum. 1984. The physiology and pathophysiology of gastric emptying in humans. Gastroenterology 86:1592-1610.

Moeller, R. B., J. Adaska, J. Reynolds, and P. C. Blanchard. 2013. Systemic bovine herpesvirus 1 infections in neonatal dairy calves. J. Vet. Diagn. Invest. 25:136-141. https://doi.org/10.1177/ 1040638712470448.

Morgado, A. A., G. R. Nunes, A. S. Martins, S. C. F. Hagen, P. H. M. Rodrigues, and M. C. A. Sucupira. 2014. Metabolic profile and ruminal and abomasal $\mathrm{pH}$ in sheep subjected to intravenous ranitidine. Pesqui. Vet. Bras. 34:17-22. https://doi.org/10.1590/ S0100-736X2014001300004.

Morisse, J. P., J. P. Cotte, D. Huonnic, and A. Martrenchar. 1999. Influence of dry feed supplements on different parameters of welfare in veal calves. Anim. Welf. 8:43-52.

Morisse, J. P., D. Huonnic, J. P. Cotte, and A. Martrenchar. 2000. The effect of four fibrous feed supplementations on different welfare 
traits in veal calves. Anim. Feed Sci. Technol. 84:129-136. https:/ /doi.org/10.1016/S0377-8401(00)00112-7.

Mueller, K., M. Merrall, and N. D. Sargison. 1999. Left abomasal displacement and ulceration with perforation of abdominal musculature in two calves. Vet. J. 157:95-97. https://doi.org/10.1053/ tvjl.1998.0274.

Murray, M. J. 1999. Review article: Pathophysiology of peptic disorders in foals and horses: A review. Equine Vet. J. Suppl. 29:14-18.

Nagamachi, Y., and S. C. Skoryna. 1977. Relationship between gastric mucosal pH and site of peptic ulceration. Am. J. Surg. 133:593596. https://doi.org/10.1016/0002-9610(77)90017-4.

Norton, L., P. Nolan, J. E. Sales, and B. Eiseman. 1972. A swine stress ulcer model. Ann. Surg. 176:133-138. https://doi.org/10.1097/ 00000658-197208000-00002.

Ok, M., I. Sen, K. Turgut, and K. Irmak. 2001. Plasma gastrin activity and the diagnosis of bleeding abomasal ulcers in cattle. J. Vet. Med. A Physiol. Pathol. Clin. Med. 48:563-568. https://doi.org/ 10.1046/j.1439-0442.2001.00389.x.

Osborne, A. D. 1976. Hairballs in veal calves. Vet. Rec. 99:239. https: //doi.org/10.1136/vr.99.22.444.

Overmier, J. B., and R. Murison. 2013. Restoring psychology's role in peptic ulcer. Appl. Psychol. Health Well-Being 5:5-27. https://doi org $/ 10.1111 / \mathrm{j} .1758-0854.2012 .01076 . x$

Pardon, B., B. Catry, J. Dewulf, D. Persoons, M. Hostens, K. De Bleecker, and P. Deprez. 2012b. Prospective study on quantitative and qualitative antimicrobial and anti-inflammatory drug use in white veal calves. J. Antimicrob. Chemother. 67:1027-1038. https: //doi.org/10.1093/jac/dkr570.

Pardon, B., K. De Bleecker, M. Hostens, J. Callens, J. Dewuif, and P. Deprez. 2012a. Longitudinal study on morbidity and mortality in white veal calves in Belgium. BMC Vet. Res. 8:26.

Pearson, G. R. R., D. Welchman, and M. Wells. 1987. Mucosal changes associated with abomasal ulceration in veal calves. Vet. Rec. 121:557-559. https://doi.org/10.1136/vr.121.24.557.

Prevedello, P., M. Brscic, E. Schiavon, G. Cozzi, and F. Gottardo. 2012. Effects of the provision of large amounts of solid feeds to veal calves on growth and slaughter performance and intravitam and postmortem welfare indicators. J. Anim. Sci. 90:3538-3546. https: //doi.org/10.2527/jas.2011-4666.

Räber, R., T. Kaufmann, G. Regula, A. Von Rotz, M. H. Stoffel, H. Posthaus, M. Rérat, M. Kirchhofer, A. Steiner, and C. Bähler. 2013a. Effects of different types of solid feeds on health status and performance of Swiss veal calves. I. Basic feeding with milk byproducts. Schweiz. Arch. Tierheilkd. 155:269-281. https://doi.org/ 10.1024/0036-7281/a000458.

Räber, R., T. Kaufmann, G. Regula, A. Von Rotz, M. H. Stoffel, H. Posthaus, M. Rérat, I. Morel, M. Kirchhofer, A. Steiner, and C. Bähler. 2013b. Effects of different types of solid feeds on health status and performance of Swiss veal calves. II. Basic feeding with whole milk. Schweiz. Arch. Tierheilkd. 155:283-292. https://doi .org/10.1024/0036-7281/a000459.

Roeder, B. L., M. M. Chengappa, T. G. Nagaraja, T. B. Avery, and G. A. Kennedy. 1988. Experimental induction of abdominal tympany, abomasitis, and abomasal ulceration by intraruminal inoculation of Clostridium perfringens type A in neonatal calves. Am. J. Vet. Res. 49:201-207.

Ross, J. G. 1963. Experimental infections of calves with the nematode parasite Ostertagia ostertagi. Vet. Rec. 75:129-131.

Ross, J. G., and C. Dow. 1965. The course and development of the abomasal lesions in calves experimentally infected with the nematode parasite Ostertagia ostertagi. Br. Vet. J. 121:228-233.

Ruis-Heutinck, L., and C. G. Van Reenen. 2000. Wateropname door witvleeskalveren kan hoog oplopen. Praktijkonderzoek 6:28-30.

Rushen, J., and G. Mason. 2006. A decade-or-more's progress in understanding stereotypic behaviour. Pages 1-18in Stereotypic Animal Behaviour: Fundamentals and Applications to Welfare. 2nd ed. G. Mason and J. Rushen, ed. CAB International, Wallingford, UK.

Sanford, S. E., and G. K. A. Josephson. 1988. Perforated abomasal ulcers in post-parturient Jersey cows. Can. Vet. J. 29:392.
Sasaki, H., T. Goyama, Y. Noda, K. Matsumoto, Y. Kobayashi, and H. Inokuma. 2012. Perforating abomasal ulcer caused by yolk sac tumor in a Holstein calf. J. Vet. Diagn. Invest. 24:804-806. https: //doi.org/10.1177/1040638712448789.

Semrad, S. D., and R. Dubielzig. 1994. Effect of repeated administration of tirilazad mesylate on healthy and endotoxemic calves: A pilot study. Can. J. Vet. Res. 58:67-70.

Smith, D. F., L. Munson, and H. N. Erb. 1983. Abomasal ulcer disease in adult dairy cattle. Cornell Vet. 73:213-224.

Smith, D. F., L. Munson, and H. N. Erb. 1986. Predictive values for clinical signs of abomasal ulcer disease in adult dairy cattle. Prev. Vet. Med. 3:573-580. https://doi.org/10.1016/0167-5877(86)90035 $-8$.

Smith, J. M. B. 1966. Letters to the editor: Candida infection in animals. N. Z. Vet. J. 14:71. https://doi.org/10.1080/00480169.1966 .33635 .

Snider, T. G., J. C. Williams, P. A. Karns, H. E. Trammell, and T. L. Romaire. 1985. Synergistic influence of Ostertagia ostertagi and Trichostrongylus axei on Ostertagia ostertagi larvae inhibition and abomasal lesions in cattle. Am. J. Vet. Res. 46:1748-1752.

Snider, T. G., J. C. Williams, D. S. Sheehan, and R. H. Fuselier. 1981. Plasma pepsinogen, inhibited larval development, and abomasal lesions in experimental infections of calves with Ostertagia ostertagi. Vet. Parasitol. 8:173-183. https://doi.org/10.1016/0304 -4017(81)90045-5.

Songer, J. G., and D. W. Miskimins. 2005. Clostridial abomasitis in calves: Case report and review of the literature. Anaerobe 11:290 294. https://doi.org/10.1016/j.anaerobe.2004.12.004.

Stokka, G., and L. Perino. 2000. The riddle of abomasal ulcers. Beef $36: 8$.

Suarez-Mena, F. X., A. J. Heinrichs, C. M. Jones, T. M. Hill, and J. D. Quigley. 2016. Straw particle size in calf starters: Effects on digestive system development and rumen fermentation. J. Dairy Sci. 99:341-353. https://doi.org/10.3168/jds.2015-9884.

Tajik, J., S. Nazifi, M. Heidari, and M. Babazadeh. 2012. Evaluation of serum proteins in water buffaloes (Bubalus bubalis) with abomasal ulcer. Asian J. Anim. Vet. Adv. 7:277-282. https://doi.org/10 .3923/ajava.2012.277.282.

Tanwar, R. K., A. Chahar, Fakhruddin, A. P. Singh, and D. K. Bihani. 2009. Abomasal ulcers in cattle. Vet. Pract. 10:39-40.

Taylor, L. M., J. J. Parkins, J. Armour, P. H. Holmes, K. Bairden, A. M. Ibarra-Silva, S. K. Salman, and P. N. McWilliam. 1989. Pathophysiological and parasitological studies on Ostertagia ostertagi infections in calves. Res. Vet. Sci. 46:218-225.

Tharwat, M., and A. F. Ahmed. 2012. Abomasal ulceration in buffaloes and cattle: Clinico-biochemical and pathological findings. J. Anim. Vet. Adv. 11:1327-1331. https://doi.org/10.3923/javaa 2012.1327.1331

Tulleners, E. P., and G. F. Hamilton. 1980. Surgical resection of perforated abomasal ulcers in calves. Can. Vet. J. 21:262-264.

Uchida, M., M. Takayama, Y. Kato, S. Tsuchiya, S. Horie, and K. Watanabe. 1999. A novel method to produce extensive gastric antral ulcer in rats: Pharmacological factors involved in the etiology of antral ulceration. J. Physiol. Paris 93:437-442. https://doi.org/ 10.1016/S0928-4257(99)00116-3.

Vajda, V., I. Maskal'ová, and A. Tesfaye. 2007. Acid-base homeostasis of blood and $\mathrm{pH}$ of abomasum in calves fed non-acidified and acidified milk replacer. Czech J. Anim. Sci. 52:96-102.

Valgaeren, B. R., B. Pardon, B. Flahou, S. Verherstraeten, E. Goossens, L. Timbermont, F. Haesebrouck, R. Ducatelle, F. Van Immerseel, and P. R. Deprez. 2013. Prevalence and bacterial colonisation of fundic ulcerations in veal calves. Vet. Rec. 172:269. https:/ /doi.org/10.1136/vr-2012-101371.

Van der Mei, J. 1985. The incidence of abomasal lesions in veal calves fattened in two housing systems and fed with or without straw pellets. Dtsch. Tierarztl. Wochenschr. 92:463-465.

Van Immerseel, F., B. Pardon, S. Maes, M. Heyndrickx, L. Timbermont, F. Boyen, F. Haesebrouck, R. Ducatelle, and P. Deprez. 2010. Isolation of a clonal population of Clostridium perfringens type A from a Belgian Blue calf with abomasal ulceration. J. 
Comp. Pathol. 143:289-293. https://doi.org/10.1016/j.jcpa.2010 .02.004.

Van Putten, G. 1982. Welfare in veal calf units. Vet. Rec. 111:437-440. https://doi.org/10.1136/vr.111.19.437.

Vatn, S., and M. J. Ulvund. 2000. Abomasal bloat, haemorrhage and ulcers in young Norwegian lambs. Vet. Rec. 146:35-39. https://doi .org/10.1136/vr.146.2.35.

Veissier, I., A. Boissy, A. M. DePassillé, J. Rushen, C. Van Reenen, S. Roussel, S. Andanson, and P. Pradel. 2001. Calves' responses to repeated social regrouping and relocation. J. Anim. Sci. 79:25802593. https://doi.org/10.2527/2001.79102580x.

Veissier, I., P. Chazal, P. Pradel, and P. Le Neindre. 1997. Providing social contacts and objects for nibbling moderates reactivity and oral behaviors in veal calves. J. Anim. Sci. 75:356-365. https://doi .org/10.2527/1997.752356x.

Veissier, I., A. R. Ramirez de la Fe, and P. Pradel. 1998. Nonnutritive oral activities and stress responses of veal calves in relation to feeding and housing conditions. Appl. Anim. Behav. Sci. 57:35-49. https://doi.org/10.1016/S0168-1591(97)00108-1.

Walsh, P., F. R. Carvallo Chaigneau, M. Anderson, N. Behrens, H. McEligot, B. Gunnarson, and L. J. Gershwin. 2016. Adverse effects of a 10-day course of ibuprofen in Holstein calves. J. Vet. Pharmacol. Ther. 39:518-521. https://doi.org/10.1111/jvp.12295.

Webb, L. E. 2014. Food for rumination-Developing novel feeding strategies to improve the welfare of veal calves. Wageningen University, Wageningen, the Netherlands.

Webb, L. E., E. A. M. Bokkers, L. F. M. Heutinck, B. Engel, W. G. Buist, T. B. Rodenburg, N. Stockhofe-Zurwieden, and C. G. Van Reenen. 2013. Effects of roughage source, amount, and particle size on behavior and gastrointestinal health of veal calves. J. Dairy Sci. 96:7765-7776. https://doi.org/10.3168/jds.2012-6135.

Webb, L. E., E. A. M. Bokkers, L. F. M. Heutinck, and C. G. Van Reenen. 2010. Comparing the effects of different roughage diets on grooming behaviour and hairball prevalence in veal calves. Page 16 in Proc. 44th Congr. Int. Soc. Appl. Ethol. (ISAE), Uppsala, Sweden. L. Lidfors, H. Blokhuis, and L. Keeling, ed. Wageningen Academic Publishers, Wageningen, the Netherlands.

Webb, L. E., B. Engel, H. Berends, C. G. Van Reenen, W. J. J. Gerrits, I. J. M. De Boer, and E. A. M. Bokkers. 2014. What do calves choose to eat and how do preferences affect behaviour? Appl. Anim. Behav. Sci. 161:7-19. https://doi.org/10.1016/j.applanim .2014.09.016.

Webb, L. E., C. G. Van Reenen, H. Berends, B. Engel, I. J. M. De Boer, W. J. J. Gerrits, and E. A. M. Bokkers. 2015. The role of solid feed amount and composition and of milk replacer supply in veal calf welfare. J. Dairy Sci. 98:5467-5481. https://doi.org/10 $.3168 /$ jds.2014-8547.

Weiner, H. 1996. Use of animal models in peptic ulcer disease. Psychosom. Med. 58:524-545. https://doi.org/10.1097/00006842 $-199611000-00002$.

Welchman, D. D. 1986. Associations between feeding, housing and the incidence of abomasal ulcers in veal calves. Proc. Nutr. Soc. 45:32A.

Welchman, D. D., and G. N. Baust. 1987. A survey of abomasal ulceration in veal calves. Vet. Rec. 121:586-590. https://doi.org/10 $.1136 /$ vr.121.25-26.586.

Wensing, T., H. J. Breukink, and S. Van Dijk. 1986. The effect of feeding pellets of different types of roughage on the incidence of lesions in the abomasum of veal calves. Vet. Res. Commun. 10:195-202. https://doi.org/10.1007/BF02213981.

Wiepkema, P. R. 1985. Over gedragsstoornissen bij dieren in de veehouderij. Tijdschr. Diergeneeskd. 110:12-20.

Wiepkema, P. R., K. K. Van Hellemond, P. Roessingh, and H. Romberg. 1987. Behaviour and abomasal damage in individual veal calves. Appl. Anim. Behav. Sci. 18:257-268. https://doi.org/10 .1016/0168-1591(87)90221-8.

Woodbury, M. R., and N. M. A. Parry. 2009. Abomasal parasite syndrome in North American elk (Cervus elaphus canadensis). N. Z. Vet. J. 57:235-240. https://doi.org/10.1080/00480169.2009.36908.

Woodford, S. T., H. D. Whetstone, M. R. Murphy, and C. L. Davis 1987. Abomasal $\mathrm{pH}$, nutrient digestibility, and growth of Holstein bull calves fed acidified milk replacer. J. Dairy Sci. 70:888-891. https://doi.org/10.3168/jds.S0022-0302(87)80088-7.

Wray, C., and J. R. Thomlinson. 1968. Abomasal ulceration in calves. Vet. Rec. 83:80.

Würbel, H., R. Bergeron, and S. Cabib. 2006. The coping hypothesis of stereotypic behaviour. Pages 14-15 in Stereotypic Animal Behaviour: Fundamentals and Applications to Welfare. 2nd ed. G. Mason and J. Rushen, ed. CAB International, Wallingford, UK.

Yandrapu, H., and J. Sarosiek. 2015. Protective factors of the gastric and duodenal mucosa: An overview. Curr. Gastroenterol. Rep. $17: 24$.

Yang, C., C. Gibbs, L. Xiao, and C. R. Wallace. 1993. Prevention of pathophysiologic and immunomodulatory effects of gastrointestinal nematodiasis in calves by use of strategic anthelmintic treatments. Am. J. Vet. Res. 54:2048-2055.

Yeomans, N. D., and J. Næsdal. 2008. Systematic review: Ulcer definition in NSAID ulcer prevention trials. Aliment. Pharmacol. Ther. 27:465-472. https://doi.org/10.1111/j.1365-2036.2008.03610.x. 